\section{Crabapple and Lilac Growth and Root-zone Temperatures in Northern Nursery Production Systems}

\author{
Catherine A. Neal ${ }^{1}$ \\ University of New Hampshire, Department of Biological Sciences, G36 SLS, \\ 38 Academic Way, Durham, NH 03824
}

Additional index words. Malus, Syringa vulgaris, container nursery, pot in pot, bag in pot, above-ground system, woody plants, tree establishment, root morphology

\begin{abstract}
Crabapple (Malus 'Donald Wyman') and common lilac (Syringa vulgaris 'Monge') were grown from liners to marketable size in five production systems: fieldgrown, plastic container, pot-in-pot (PiP), bag-in-pot (BiP), and above-ground system (AGS). The objectives were to compare growth in modified container systems, which could potentially eliminate overwintering requirements in northern production nurseries and to compare the effects on tree root growth during landscape establishment. There were no significant differences in crabapple root or shoot mass after two seasons except PiP dry root weights exceeded field-grown trees. For lilacs, there were significant differences in growth and shoot dry weight with field-grown and PiP plants being largest. PiP root-zone temperatures (RZTs) were similar to field-grown RZTs. Container, BiP, and AGS systems all exceeded lethal high and low RZT thresholds, resulting in root damage. Five trees from each treatment were transplanted into a low-maintenance landscape and dug up 3 years later. There were no significant differences in top growth, but the effects of the production systems were evident in the root architecture. BiP and field-grown trees had fewest root defects and the greatest number of roots extending into the landscape soil.
\end{abstract}

Container production of trees and shrubs has increased rapidly in the past two decades and has surpassed field production in many parts of the country (Hodges et al., 2008). Advantages of container production over field production include more efficient use of land and labor, more control of the growing environment, and extended planting and harvesting seasons. Plants are easier to handle and ship, more attractive at retail outlets, and easy to transplant. The entire root system is transplanted, unlike field-dug material in which less than $10 \%$ of the roots may be retained in the harvested root ball (Gilman, 1988; Watson and Himelick, 1982).

Inputs for container production, however, are greater than for field production. Pots, growing media, and the necessity for increased precision in irrigation and fertiliza-

Received for publication 6 Apr. 2009. Accepted for publication 6 Oct. 2009.

This is Scientific Contribution Number 2414 from the New Hampshire Agricultural Experiment Station.

Funding was provided in part by the New Hampshire Horticulture Endowment, New England Grows, UNH Agricultural Experiment Station, and UNH Cooperative Extension. Geotextile products were donated by Texel, Inc., Quebec, Canada.

Mention of a trademark, proprietary product, or vendor does not constitute a guarantee or warranty of the product by the author and does not imply its approval to the exclusion of other products or vendors that also may be suitable.

${ }^{1}$ Extension Professor and Specialist.

e-mail cathy.neal@unh.edu.
England, causing root death late in the growing season.

Pot-in-pot $(\mathrm{PiP})$ production systems were developed in the southeastern United States for prevention of wind throw and moderation of supraoptimal media temperatures (Ruter, 1993). The PiP system consists of socket pots recessed in the ground into which liner pots containing the plants are inserted. The liner pots are pulled and sold with the plants; the socket pots are a semipermanent installation. Compared with field-grown trees, PiP provides potential labor savings and provides a supply of fresh trees for market all season, whereas field-grown trees are harvested during the dormant season and held for sale in the nursery yard.

Shoot growth increases of up to $20 \%$ and root mass increases of up to $50 \%$ have been reported for woody plants grown in $\mathrm{PiP}$ compared with traditional container production (London et al., 1998; Ruter 1998a, 1998b). Adrian et al. (1998) reported that PiP "was least costly on a per-harvested plant basis due to less intensive, labor-saving cultural practices and the ability to grow larger plants quickly" compared with field or container production methods. However, the initial expense of PiP installation can be a deterrent to adoption of this system (Hall et al., 2002).

Modifications of PiP include bag-in-pot (BiP) and above-ground system (AGS), in which the socket pots are above ground rather than recessed. In $\mathrm{BiP}$, the socket is a standard nursery pot and the insert is a geotextile bag. The AGS socket pot is a truncated cone that surrounds the standard plastic pot used as the insert. An air space between the inner and outer pots potentially provides some insulating value and protects the inner pot from direct solar radiation.

Little research has previously been done to test the suitability of PiP, BiP, or AGS production for northern climates, although several nurseries have installed PiP production areas and grown crops successfully. The objectives of this research were to compare growth of two woody species commonly grown in northern nurseries (crabapple and lilac) in field, container, PiP, BiP, and AGS production systems and to monitor root-zone temperatures (RZTs) to answer the following questions for northern New England and similar cold climates:

1. Is growth enhanced in PiP or other modified container systems as compared with traditional field or container production systems?

2. Do summer RZTs in containers exceed the upper threshold for root viability, and how do modified container systems affect supraoptimal temperatures?

3. Can plants be overwintered in $\mathrm{PiP}$ or other container systems without exposing roots to sublethal temperatures?

4. Do PiP or other production systems confer an advantage in plant survival and establishment when transplanted into the landscape? 
Table 1. Summary of average monthly temperature, total precipitation, and irrigation applied during 2001 and 2002 growing seasons. ${ }^{\mathrm{z}}$

\begin{tabular}{|c|c|c|c|c|c|c|c|c|c|c|c|}
\hline Parameter & Unit & Production system & $\mathrm{Yr}$ & May & June & July & August & September & October & Season total & Annual total \\
\hline \multirow[t]{2}{*}{$\overline{\text { Average temp }}$} & ${ }^{\circ} \mathrm{C}$ & & 2001 & $n a^{x}$ & 20.3 & 20.2 & 22.7 & 17.1 & 11.0 & 18.2 & $n r^{w}$ \\
\hline & & & 2002 & 13.1 & 17.9 & 22.4 & 23.0 & 18.6 & 8.8 & 18.2 & 9.6 \\
\hline \multirow[t]{2}{*}{ Precipitation $^{\mathrm{y}}$} & $\mathrm{mm}$ & & 2001 & na & 134.4 & 80.3 & 32.8 & 66.0 & 39.9 & 353.3 & 1005.8 \\
\hline & & & 2002 & 96.0 & 135.6 & 32.8 & 40.6 & 85.6 & 113.5 & 408.2 & 1018.5 \\
\hline \multirow[t]{4}{*}{ Irrigation } & $\mathrm{L} / \operatorname{pot}^{\mathrm{v}}$ & Containers $^{\mathrm{u}}$ & 2001 & na & 79.5 & 85.2 & 82.5 & 39.8 & 32.9 & 319.9 & \\
\hline & & & 2002 & 19.7 & 13.3 & 59.6 & 106.0 & 56.0 & 0.0 & 234.9 & \\
\hline & $\mathrm{L} /$ plant & Field-grown & 2001 & na & 64.0 & 53.0 & 76.1 & 39.8 & 23.1 & 255.9 & \\
\hline & & & 2002 & 19.7 & 13.3 & 59.6 & 106.0 & 39.8 & 0.0 & 218.7 & \\
\hline
\end{tabular}

${ }^{\mathrm{z}}$ Irrigation records were kept for crabapple production study during this time. Lilacs received $5 \%$ to $10 \%$ less irrigation water than crabapples during 2001 and 2002 .

${ }^{\mathrm{y}}$ Average monthly temperature and total monthly precipitation data for southern New Hampshire (Natl. Oceanic and Atmospheric Administration, 2001, 2002). ${ }^{x}$ na; May 2001 data not applicable because trial did not begin until 5 June 2001.

${ }^{\mathrm{w}} \mathrm{nr}=$ no record.

'Irrigation volume calculated from the number of irrigation events each mo., their durations, and the emitter application rate (26.5 L/hour).

"Containers refers to all potted production systems in the trial, i.e., all systems other than field-grown.

\section{Materials and Methods}

Bare-root crabapple (Malus 'Donald Wyman') whips (0.6 m tall, $1.1 \mathrm{~cm}$ trunk diameter) were planted on 5 June 2001 into a new nursery block at the University of New Hampshire Horticultural Research Farm in Durham, NH (lat. $43.14^{\circ} \mathrm{N}$, long. $70.93^{\circ} \mathrm{W}$ ). Lilacs (Syringa vulgaris 'Monge') were planted from No. $1\left(2838 \mathrm{~cm}^{3}\right)$ containers in an adjacent production area on 12 July. The experimental design for each species was a randomized complete block with five blocks and two replicates of each treatment per block for a total of 10 plants per treatment.

The treatments in both trials were as follows:

Field-grown: Plants were transplanted directly into native soil (Charlton fine sandy loam, pH 6.9), which had been cover-cropped with ryegrass the previous season.

Container: The container treatment was a typical nursery production system with containers set directly on the soil surface. After experiencing wind throw problems during the second growing season, each container was staked with a steel reinforcement rod to prevent further blow over. Container plants were overwintered in an unheated poly house covered with white plastic film between 18 Oct. 2001 and 1 May 2002 and between 1 Nov. 2002 and 15 Apr. 2003.

PiP: Socket pots were installed in the field by hand-digging holes, setting the pots, and backfilling soil around the pot to within $7.6 \mathrm{~cm}$ of the top. The plants were planted in samesized liner pots inserted into the socket pots. Squares of copper hydroxide-treated geotextile fabric (Texel Inc., Quebec, Canada) were placed between the inner and outer pots to prevent rooting out through the drainage holes. PiP plants were overwintered in place.

$B i P$ : Plants were planted into copper hydroxide-treated, rounded geotextile bags $\left(21,600 \mathrm{~cm}^{3}\right)$ (Texel Inc.) and placed into plastic containers. They were overwintered in the unheated poly house along with the container treatment.

AGS (Nursery Supplies Inc., Chambersburg, $P A)$ : This system consisted of a tapered above-ground socket pot with a broad base for stability, into which the container plant was inserted. The intact double containers

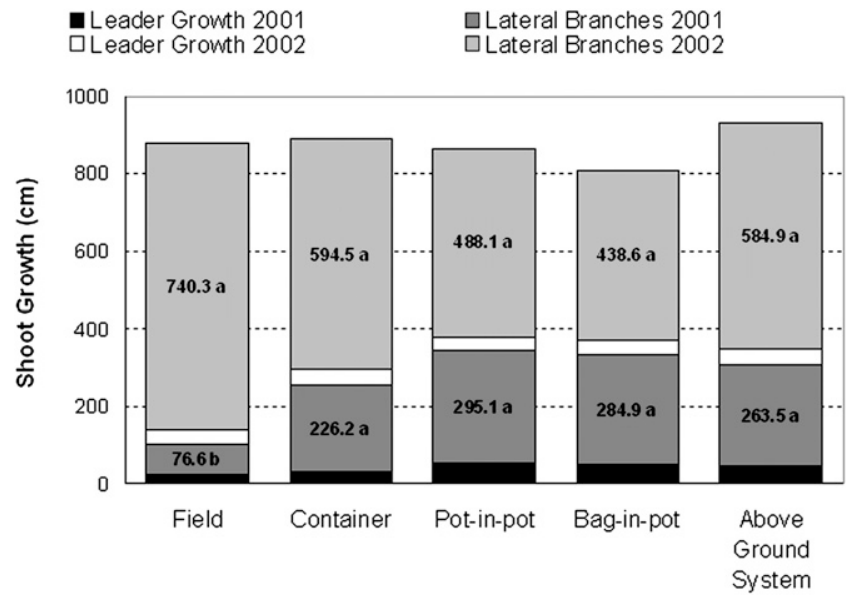

Fig. 1. Bar height represents the mean total shoot extension per crabapple tree for each treatment during the trial period. Each bar is the sum of the increase in length of the central leader in $2001+$ increase in total length of lateral branches 2001 + increase in length of central leader 2002 + increase in total length of lateral branches 2002. Means within categories not followed by the same letter are significantly different at $P \leq 0.05$ by Tukey's pairwise comparison $(\mathrm{n}=10$ except for lateral branches 2002 in which $\mathrm{n}=4$ for pot-in-pot, bag-in-pot, and above-ground system and $\mathrm{n}=5$ for field and container).

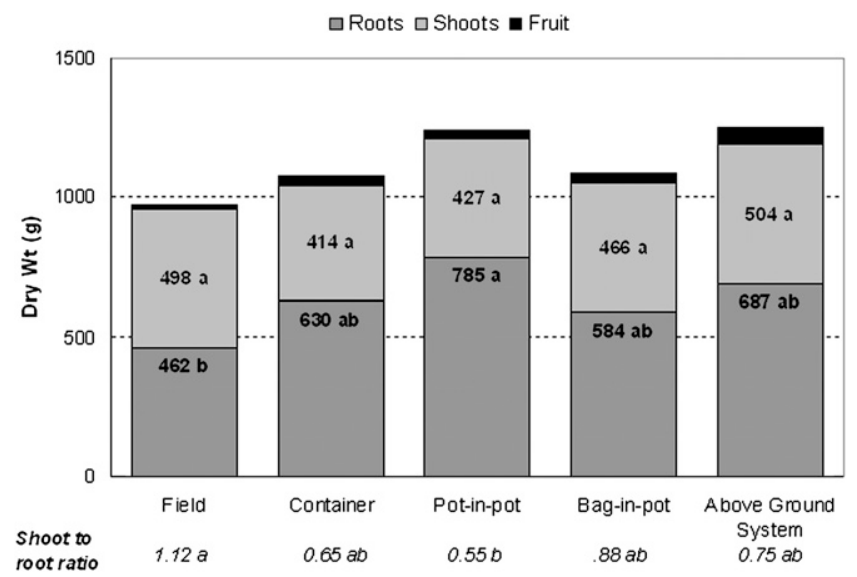

Fig. 2. Dry weights of roots, shoots, and fruit of crabapple trees harvested after leaf fall in Nov. 2002. Means within categories not followed by the same letter are significantly different at $P \leq 0.05$ by Tukey's pairwise comparison $(\mathrm{n}=10)$.

were moved and overwintered in the unheated poly house along with the container and BiP treatments.

Pots for the container treatment, the socket and liner pots in the PiP system, the outer pot for BiP, and the liner pot for AGS were No. $7\left(24,600 \mathrm{~cm}^{3}\right)$ black plastic containers (Nursery Supplies, Inc.). The interior surface of the PiP and AGS liner pots and the standard container treatment were painted 
with latex paint containing copper hydroxide (Spinout; Griffin Chemical Corp., Valdosta, GA) to prevent root circling. The substrate was a commercial nursery mix (Conrad Fafard Inc., Agawam, MA) composed of $80 \%$ pine bark and $20 \%$ peat.

Irrigation was applied as needed with microsprayers (26.5 L/hour; Netafim Irrigation, Inc., Altamonte Springs, FL) from planting until 18 Oct. 2001, from 6 May until 20 Sept. 2002, and for lilacs from 4 June until 10 Oct. 2003. Application frequency was adjusted throughout the season based on soil moisture (measured with tensiometers), stage of plant growth, environmental conditions, and weather forecasts. Average irrigation duration was $15 \mathrm{~min}$. All treatments were on the same zone, but emitters for fieldgrown plants were blocked when irrigation was not needed. Table 1 summarizes temperature, precipitation, and irrigation records for the 2001 and 2002 growing seasons. Natural precipitation was supplemented with infrequent hand-watering during the remainder of the year when the irrigation system was off.

All plants were fertilized soon after planting with Nutricote (Chisso-Asahi Fert. Co. Ltd., Tokyo, Japan) Type 100 with minor elements $(18 \mathrm{~N}-2.6 \mathrm{P}-10 \mathrm{~K}) \quad(84 \mathrm{~g} / \mathrm{plant})$. Nutricote Type $40(16 \mathrm{~N}-2.6 \mathrm{P}-10 \mathrm{~K})(20 \mathrm{~g} /$ plant) was applied 8 May 2002 followed by Type 100 (84 g/plant) on 18 June 2002. Lilacs received another application of Type 100 (85 g/plant) on 7 May 2003.

Data recorders (Hobo H8 Outdoor/Industrial logger; Onset Computer, Pocasset, MA) were installed to record air, soil, and media temperatures every $15 \mathrm{~min}$ in one representative pot per treatment per species from 20 July 2001 through 1 July 2003. Temperature sensors were placed in the southwest quadrants of the containers, $10 \mathrm{~cm}$ deep and $2.5 \mathrm{~cm}$ inside the pot wall.

Growth response variables (including height, trunk diameter $10 \mathrm{~cm}$ above the soil surface, and annual extension of the central leader and branches) for crabapple were measured in July and November of each growing season. After two growing seasons, the crabapple trees were of marketable size according to the ANSI Z60.1 standard (American Assoc. of Nurserymen, 1996) and one tree row per block was harvested the week of 8 Nov. 2002. Field-grown trees were harvested with a manual tree digger (Tree Toad Tree Transplanters, Long Lake, MN) to obtain a consistent $61-\mathrm{cm}$ conical root ball on each tree, which provided a soil volume equivalent to the containers.

Fruits were removed from each tree, bagged, dried, and weighed. Roots were washed with a water stream from a hose. Roots and shoots from each tree were cut up, bagged, and placed in a drying room at 32 to $49{ }^{\circ} \mathrm{C}$ for 2 months. The dried roots went through a second cleaning process to eliminate more dirt and stones before being weighed. Final root-to-shoot ratios were calculated on a dry weight basis.

Trees from the second tree row in each block were transplanted into a simulated landscape situation on 11 Oct. 2002 in a randomized complete block experimental design with five blocks (rows). The spacing was $3 \mathrm{~m}$ between rows and $3 \mathrm{~m}$ between trees. The trees were watered by hand at planting and twice more during June to July 2003; after that, rainfall was above normal and no further irrigation was applied. Based on a soil test, the field was amended with $74.4 \mathrm{~kg} \cdot \mathrm{ha}^{-1}$ potassium from $\mathrm{KSO}_{4}$ a few months before transplanting. Each tree was fertilized once per year with slow-release fertilizer: $42.5 \mathrm{~g}$ of $24 \mathrm{~N}-2.6 \mathrm{P}-9.1 \mathrm{~K}$ on $15 \mathrm{Aug}$. 2003, $56.7 \mathrm{~g}$ of $16 \mathrm{~N}-1.7 \mathrm{P}-6.6 \mathrm{~K}$ on 14 June 2004 , and $56.7 \mathrm{~g}$ of $24 \mathrm{~N}-0.9 \mathrm{P}-6.6 \mathrm{~K}$ on 5 July 2005 . Each tree was mulched with 5 to $8 \mathrm{~cm}$ of wood chips from the trunk to the drip line and was pruned to maintain a central leader. On 27 Nov. 2005, the trees were dug with a tree spade so that comparisons could be made as to the extent of root escape from the original root ball and the degree of circling or bent roots. Trees were stored under an insulating blanket during the winter, then in spring, the soil was removed with a water stream and observations on root patterns were made and photographed. Height and trunk diameter were measured in the field at the beginning and end of the trial.

Lilacs were not of sufficient size after two growing seasons, so they were overwintered and grown for a third season. Lilacs were harvested 18 Nov. 2003 and stored in a cooler at 0 to $2.2{ }^{\circ} \mathrm{C}$ for 5 months before they were processed in the same manner as described previously for the crabapples. Growth index for lilac was the sum of the height plus width of the plant divided by two.

Analysis of variance (ANOVA) was performed using JMP7 software (SAS Institute, Cary, NC). Block-by-treatment interactions
A

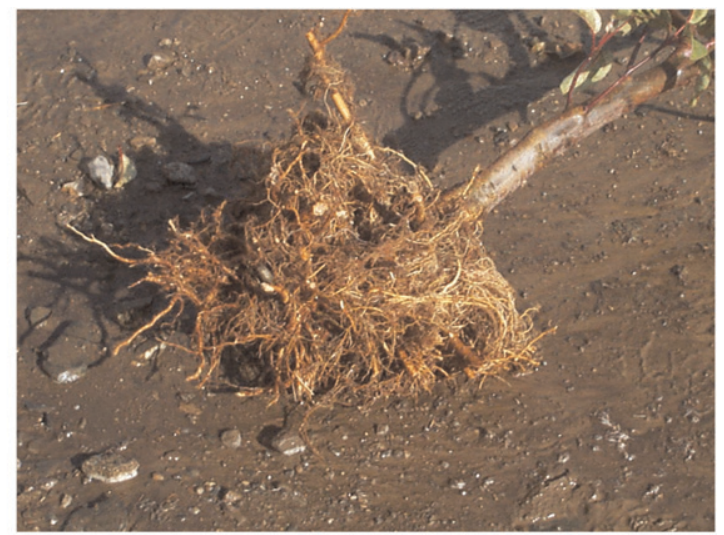

B

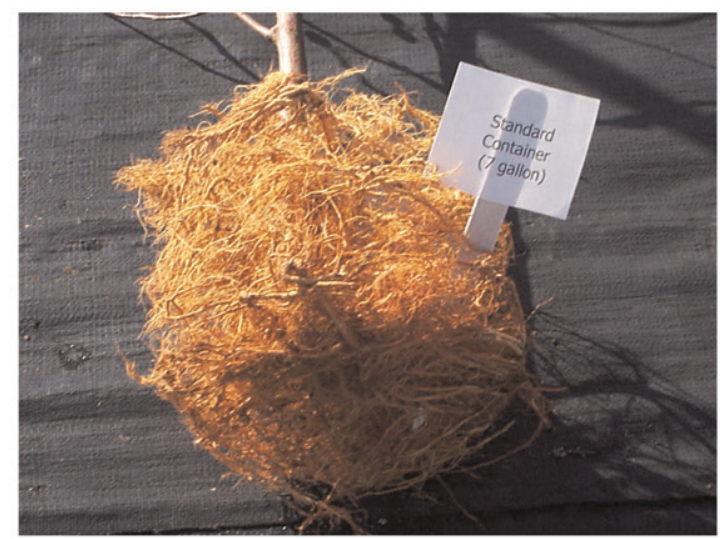

C

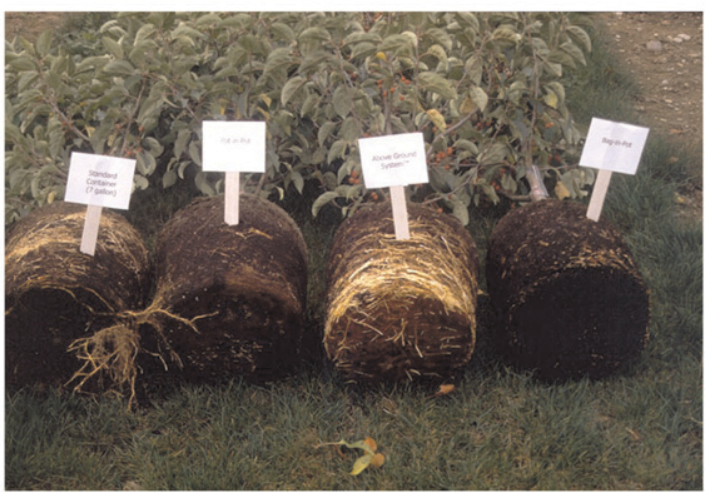

Fig. 3. Crabapple root balls at the end of production system trial. (A) Washed roots from field-grown tree; (B) washed roots from plastic container; (C) unwashed root balls; left to right, plastic container, pot-inpot, above-ground system, and bag-in-pot. 
were not significant in any analysis and so were pooled in the error terms for testing treatment and block effects. The Tukey-Kramer honestly significant difference for all pairwise mean comparisons was performed when warranted by significant differences $(P \leq$ $0.05)$ in the ANOVA.

\section{Results}

Crabapple growth responses in production. Field-grown trees were significantly slower in growth during the first growing season with a $0.36 \mathrm{~cm}(\mathrm{SE}=0.04)$ increase in trunk diameter compared with a mean of $0.82 \mathrm{~cm}$ $(\mathrm{SE}=0.02)$ for the other treatments. However, the growth rate of field-grown trees increased early in the second growing season so that there were no further significant differences in trunk diameter or shoot growth (Fig. 1) among treatments. The mean trunk diameter was $3.1 \mathrm{~cm}(\mathrm{SE}=0.04)$ at the time the crabapples were harvested and transplanted into the subsequent establishment trial.

Shoot, fruit, and total plant dry weights were not significantly different among production systems at the end of the trial. Dry root weights, however, were greatest for PiPgrown trees and were significantly greater than for field-grown trees (Fig. 2). Harvested shoot:root ratios were significantly higher for field-grown trees than for container or PiP

Table 2. Change in crabapple tree height and trunk diameter from transplanting in Oct. 2002 to termination in Nov. 2005.

\begin{tabular}{lccc}
\hline Treatment & $\begin{array}{c}\text { Tree ht } \\
\text { increase }(\mathrm{cm})\end{array}$ & $\begin{array}{c}\text { Trunk diam } \\
\text { increase }(\mathrm{cm})\end{array}$ & $\begin{array}{c}\text { Root extension } \\
\text { (number) }\end{array}$ \\
\hline Field & 59.4 & 2.3 & 44.4 \\
Container & 69.9 & 2.0 & 28.7 \\
Pot-in-pot & 87.6 & 2.2 & 22.3 \\
Bag-in-pot & 83.2 & 2.7 & 46.7 \\
Above-ground system & 62.7 & 2.3 & 31.5 \\
SE & 4.82 & 0.11 & 3.53 \\
$\operatorname{Pr}>F$ & 0.60 & 0.42 & $0.03^{\mathrm{y}}$ \\
\hline
\end{tabular}

${ }^{\mathrm{z}}$ Root extension into surrounding soil was assessed after harvesting with a tree spade by counting the number of cut roots extending radially from the surface of the original root ball. $n=5$ except $n=4$ for potin-pot as a result of mower injury on one tree.

${ }^{y}$ Although $P>F$ was significant at the $5 \%$ level; there were no significant differences within the column by Tukey's pairwise comparison $(P \leq 0.05)$.

trees, reflecting that digging root balls of field-grown trees fails to recover a large proportion of the roots.

The photos in Figure 3 show how root structure was influenced by production system and container type. The copper hydroxide paint used on the plastic containers failed to prevent extensive root circling; however, the geotextile bag was very effective in this regard. BiP root balls tended to be smaller, once washed, than those from other container systems, but $\mathrm{BiP}$ roots had very few root defects at the end of the production cycle.

Crabapple transplant study. There were no significant differences in tree height or trunk diameter increase between planting and termination of the transplant study (Table 2). All of the transplanted trees survived and grew an average of $73 \mathrm{~cm}$ in height and $2.3 \mathrm{~cm}$ in trunk diameter in 3 years. Despite the lack of measurable differences, visual observations indicated that field-grown trees were slower to establish and recover from transplant shock; i.e., wilting was noted only on field-grown trees during Spring 2003 and these trees were slower to leaf out.

Examination of the root balls 3 years later confirmed that root growth patterns after transplanting were dependent on production practices (Fig. 4). Root growth from the field-grown trees extended radially from the trunk without any interruption at the interface of the original root ball and the surrounding soil.
A

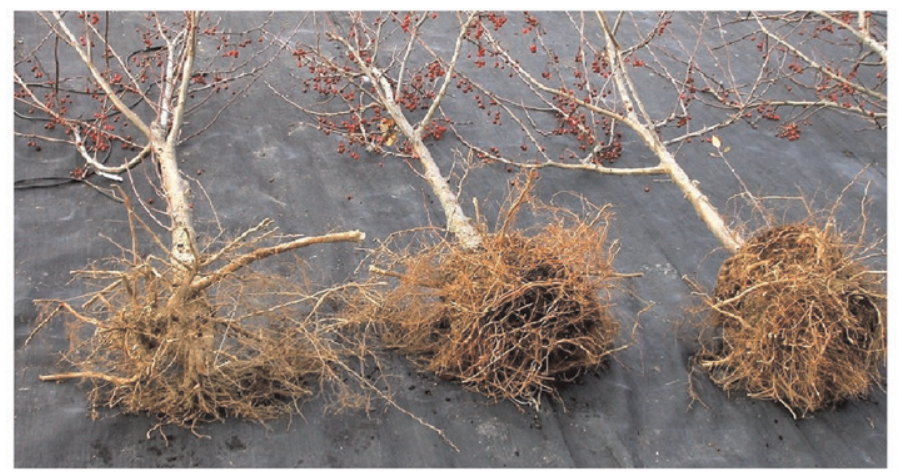

B

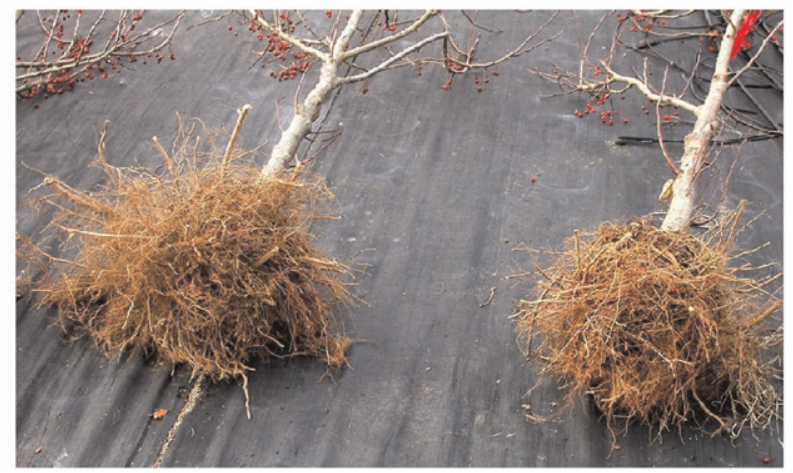

Fig. 4. Harvested roots of crabapple trees 3 years after transplanting still showed the effects of the production systems. Left to right, production systems were (A) field-grown, plastic container, pot-in-pot; (B) bag-in-pot, above-ground system. Circling roots are evident in trees from plastic containers, pot-in-pot, and above-ground system but not field-grown or bag-in-pot treatments.

Table 3. Effects of five production systems on growth and flowering of lilac over three growing seasons. ${ }^{z}$

\begin{tabular}{|c|c|c|c|c|c|c|c|c|c|c|c|}
\hline \multirow[b]{2}{*}{ Treatment } & \multicolumn{4}{|c|}{ Plant ht (cm) } & \multirow{2}{*}{$\begin{array}{c}\begin{array}{c}\text { Growth } \\
\text { index }\end{array} \\
\frac{10 \text { Oct. }}{2003}\end{array}$} & \multirow{2}{*}{$\begin{array}{c}\begin{array}{c}\text { No. of } \\
\text { panicles }\end{array} \\
\text { per plant } \\
\begin{array}{c}1 \text { June } \\
2003\end{array}\end{array}$} & $\begin{array}{l}\text { Percent } \\
\text { mortality }\end{array}$ & $\begin{array}{c}\text { Percent } \\
\text { damaged }\end{array}$ & \multirow[b]{2}{*}{$\begin{array}{l}\text { Top dry } \\
\text { wt (g) }\end{array}$} & \multirow[b]{2}{*}{$\begin{array}{l}\text { Root dry } \\
\text { wt (g) }\end{array}$} & \multirow[b]{2}{*}{$\begin{array}{l}\text { Shoot-to-root } \\
\text { ratio }\end{array}$} \\
\hline & $\begin{array}{l}\text { 19 July } \\
2001\end{array}$ & $\begin{array}{l}17 \text { July } \\
2002\end{array}$ & $\begin{array}{l}28 \text { Mar. } \\
2003\end{array}$ & $\begin{array}{c}10 \text { Oct. } \\
2003\end{array}$ & & & \multicolumn{2}{|c|}{$\begin{array}{l}\text { (attributed to } \\
\text { lilac borer) }\end{array}$} & & & \\
\hline Container & 37 & 69 & $68 \mathrm{~b}$ & $94 \mathrm{~b}$ & $84.6 \mathrm{~b}$ & $20.6 \mathrm{a}$ & 0 & 40 & $488 \mathrm{a}$ & 423 & 1.38 \\
\hline Pot-in-pot & 36 & 73 & $80 \mathrm{a}$ & $99 \mathrm{ab}$ & $88.3 \mathrm{ab}$ & $6.5 \mathrm{~b}$ & 60 & 80 & $548 \mathrm{a}$ & 513 & 1.08 \\
\hline Bag-in-pot & 36 & 68 & $67 \mathrm{~b}$ & $87 \mathrm{~b}$ & $81.0 \mathrm{~b}$ & $28.2 \mathrm{a}$ & 0 & 40 & $459 \mathrm{a}$ & 308 & 1.56 \\
\hline $\mathrm{SE}$ & 0.6 & 1.2 & 1.4 & 2.2 & 1.2 & 1.8 & na & na & 21 & 19 & 0.07 \\
\hline $\operatorname{Pr}>\mathrm{F}$ & 0.87 & 0.34 & 0.01 & 0.0002 & 0.002 & $<0.0001$ & na & na & 0.04 & 0.06 & 0.14 \\
\hline
\end{tabular}

${ }_{\mathrm{n}} \mathrm{n}=10$ observations per treatment except Oct. 2003 data and terminal data where $\mathrm{n}=4$ for pot-in-pot as a result of plant mortality attributed to insect damage. ${ }^{\mathrm{y}}$ Growth index $=(\mathrm{ht}+$ width $) / 2$ on 10 Oct. 2003.

${ }^{x}$ Means within columns not followed by the same letter are significantly different at $P \leq 0.05$ by Tukey's pairwise comparison. 
The largest roots were near the soil surface. Trees from the three plastic container systems (containers, PiP and AGS) all had apparent root defects, including circling and bent roots at the perimeters of the original root balls. BiP appeared to be very effective in pruning roots during production and preventing the formation of root defects that carried over into the landscape. Roots from the transplanted $\mathrm{BiP}$ treatments formed a dense fibrous root system and were able to extend without impediment into the surrounding soil. The number of roots that had extended into the landscape soil was greatest for $\mathrm{BiP}$ and field-grown trees (Table 2).

Lilac growth responses. Plant height did not differ between production systems initially or after 1 year (Table 3 ). There were significant differences in height at the end of the second and third growing seasons as well as final growth index with field-grown and PiP plants being the largest. The root systems of lilacs were dense and fibrous compared with the thicker, more woody roots of crabapples. In both species, PiP had the highest root weights and lowest shoot:root ratios of all the treatments. Crabapple trees allocated more resources to roots than to shoots, whereas lilacs produced more shoot weight than root weight, resulting in shoot:root ratios over 1.0 for dormant lilacs and under 1.0 for dormant crabapples.

In May 2003, five of the 10 PiP lilacs budded out slowly, displaying very weak vegetative growth and few flowers (Table 3 ). Four of the five subsequently died. Based on the symptoms (holes and tunnels in lower stem portions) observed and rated during final processing of the plants, the damage was attributed to lilac borer. The field-grown lilacs also aborted most of their flower buds, presumably as a result of cold, but vegetative growth was strong and no plants died. All of the plants overwintered in the poly house survived, flowered prolifically, and put on strong spring growth, but borer damage was noted at the end in $30 \%$ to $40 \%$ of the plants. Why the PiP plants suffered more borer damage than other treatments is unknown.

The fact that panicle number was greatly affected by production system may be of concern to retailers who know that plants in full bloom outsell plants with no or few blooms. It is surprising that a cold-hardy variety like 'Monge' experienced such a large reduction in flowering in field and PiP treatments compared with treatments that overwintered in the poly house.

Root-zone temperatures. Minimum, maximum, and mean air and RZTs are shown in Figure 5 for the period in which the crabapples were in production. The highest hourly air temperature (average of four measurements per hour) was $38.8^{\circ} \mathrm{C}$ on 3 July 2002 . RZTs reached a high of $49.6^{\circ} \mathrm{C}$ in containers, $44.4{ }^{\circ} \mathrm{C}$ in AGS, $43.9{ }^{\circ} \mathrm{C}$ in BiP, $37.4{ }^{\circ} \mathrm{C}$ in PiP, and $32.8^{\circ} \mathrm{C}$ in the soil at a $10-\mathrm{cm}$ depth. Supraoptimal RZTs in AGSs were most frequent between late August and early October as a result of clear, sunny days and the low angle of incidence of the sun

A

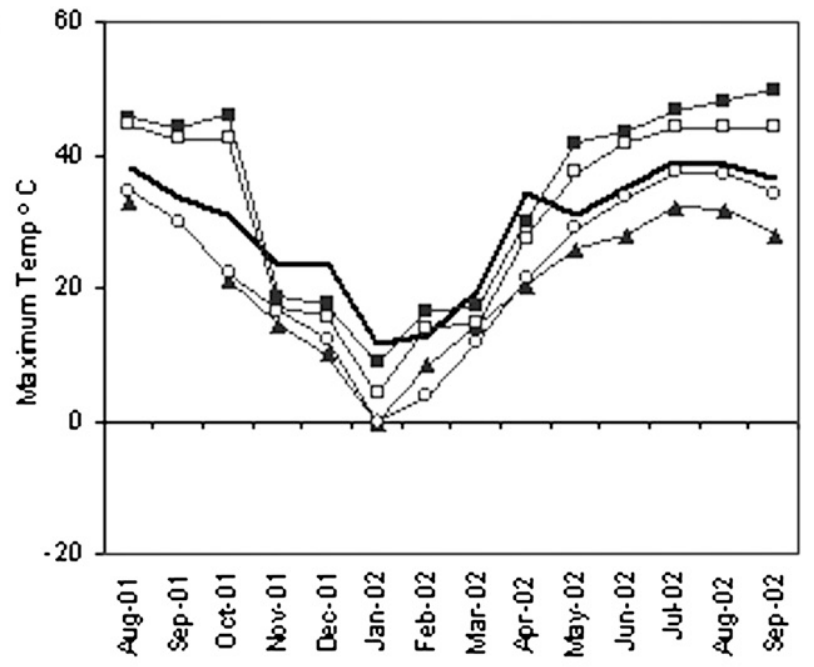

B

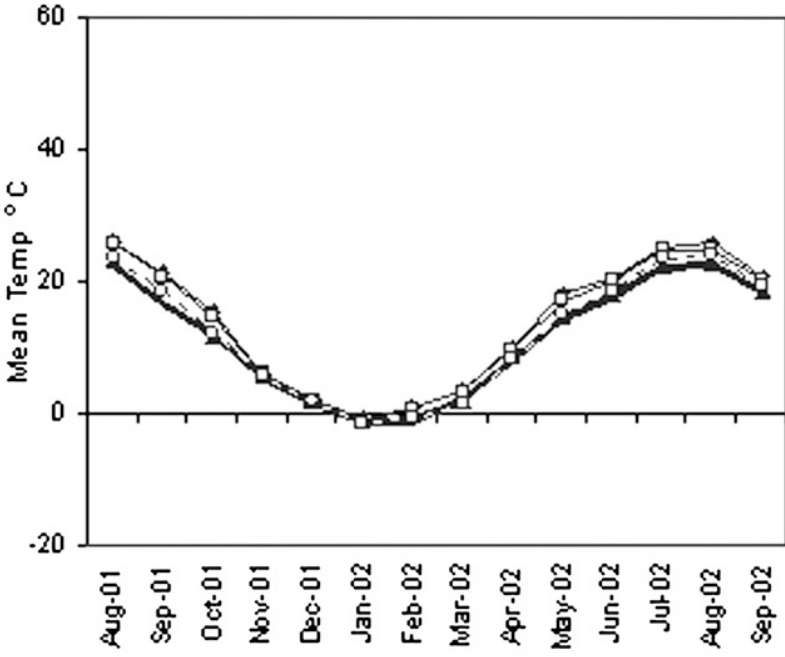

C

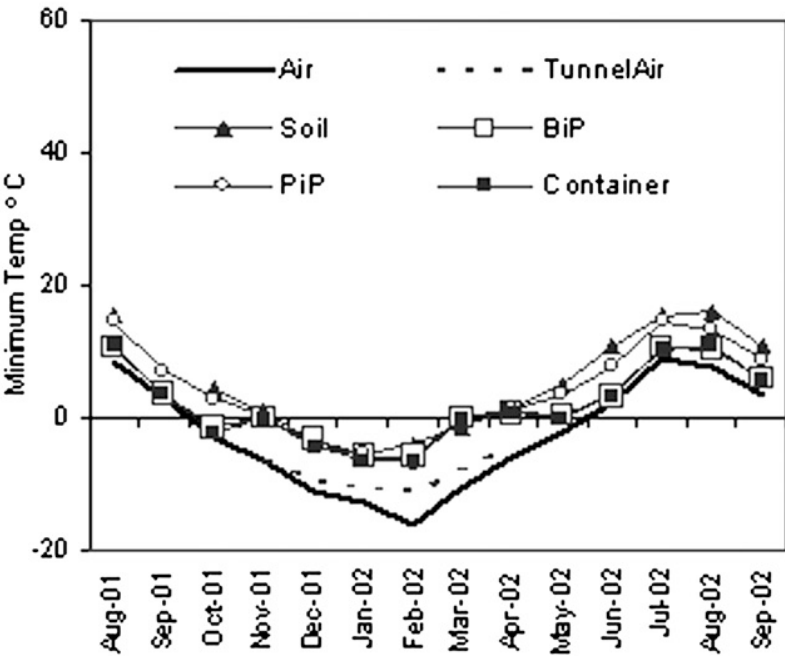

Fig. 5. (A) Maximum, (B) mean, and (C) minimum root-zone temperatures at 10-cm depth of soil or substrate in each crabapple production system compared with ambient air temperatures, Aug. 2001 to Sept. 2002. Maximum and minimum temperatures are the highest and lowest average hourly temperatures (average of four records/hour) each month; one sensor per treatment. For monthly means, $\mathrm{n}=1887-2979$ except May 2002, which represents only 16 to 30 May $(\mathrm{n}=1479)$. Aboveground system (AGS) data not shown as a result of several periods of sensor malfunction. Tunnel air temperatures are the ambient temperatures in the poly tunnel when the container, bag-in-pot (BiP), and AGS treatments were inside for winter protection, December to April.

striking the container wall, whereas soil and PiP RZTs were highest in July with direct overhead radiation. Visual observation of the root systems confirmed areas of root death in the southwest quadrants of plastic containers.

Winter 2001-2002 was relatively mild $\left(-16.0^{\circ} \mathrm{C}\right.$ minimum air temperature) but there 
was little snow cover. Minimum RZTs in PiP were were $-6.8^{\circ} \mathrm{C}$ compared with $-5.3{ }^{\circ} \mathrm{C}$ in field soil. Plants in the poly house were exposed to minimum ambient air temperatures of -11.1 and RZTs in containers, BiP, and AGS treatments fluctuated by as much as 16.5 ${ }^{\circ} \mathrm{C}$ per day during late winter. The minimum hourly RZTs were $-6.3,-5.8$, and $-3.8^{\circ} \mathrm{C}$ for container, BiP, and AGS, respectively.

Winter 2002-2003, during which only the lilacs remained in the production trial, was colder overall than the previous year. Outside air temperatures fell below $-17.8{ }^{\circ} \mathrm{C}$ on 20 nights and reached a minimum of $-27.2^{\circ} \mathrm{C}$. Inside the poly house, air temperatures ranged from -16.7 to $30.6{ }^{\circ} \mathrm{C}$. RZTs in the poly house reached a minimum of $-11.7^{\circ} \mathrm{C}$ in $\mathrm{BiP}$ and AGS and $-10{ }^{\circ} \mathrm{C}$ in containers. Data loggers for PiP and field soil failed so no data are available for these treatments for Winter 2002-2003.

\section{Discussion}

Crabapple and lilac showed few significant growth differences associated with the production systems. Although field-grown crabapple shoot growth rates were reduced during the first season, faster growth during the second season resulted in all treatments reaching saleable size at the same time. Lilac borer damage prevented making strong conclusions from the lilac trial, but field-grown and PiP plants were largest. Root weights in both crabapple and lilac were greatest in PiP, although not significantly more than the other container systems. Significant enhancement of growth as reported in the Southeast for PiP-grown trees and shrubs was not documented in this northern New England trial. This could be the result of differences in the species tested, extended duration of supraoptimal RZTs in the Southeast, or differences in water relations.

Solar radiation on clear days between July and mid-October frequently elevated container substrate temperatures to 37.8 to $48.9{ }^{\circ} \mathrm{C}$, resulting in root death inside the container wall in the southwest pot quadrant. The PiP system exceeded the lethal high threshold for roots at $10-\mathrm{cm}$ depth, but associated root death was not observed in this treatment because deeper roots were protected. Maximum AGS and BiP RZTs were only slightly lower than plastic containers and failed to prevent temperatures from surpassing the lethal threshold. Supraoptimal temperatures in black plastic containers occurred earlier in the day and had higher peaks and longer durations than in any other treatments.

Minimum winter RZTs in PiP were a few degrees lower than soil temperatures and no plant death or injury was attributed to low RZTs in these trials. There was no evidence to indicate that additional winter protection is required for PiP nursery stock as long as locally adapted plant genotypes are grown. AGS and BiP systems, however, provided very little protection from the cold; therefore, the plants should be overwintered in a protected environment like other containergrown stock if grown in AGSs. The root distribution in BiP was effectively modified by the geotextile fabric liner; thus, fewer roots were exposed to lethal high RZTs at the container wall. Placing the geotextile bag in a socket pot below ground could be expected to combine the root-pruning benefits of $\mathrm{BiP}$ with the greater insulating properties of PiP.

Although the growth rate increase associated with PiP systems in southern climates was not observed here, PiP appears to be a useful production system for northern nurseries. The labor savings associated with not having to stack and cover large container material for overwintering is economically advantageous to producers. Likewise, PiP prevents wind throw and associated mechanical damage as well as associated labor costs for uprighting the plants on a frequent basis. Compared with field production, harvesting and handling is easier and it makes fresh landscape material available all season; however, some growers and landscapers still prefer field-grown material over that produced in any container system.

The benefits of summer and winter RZT moderation in PiP, which resulted in greater root dry weights and lower shoot:root ratios, could be expected to confer an advantage when transplanted to the landscape. The crabapple transplant study described here did not provide direct evidence of that, however, because all the trees survived and grew at similar rates. Differences in root growth patterns and defects as determined by production systems were still evident when roots were examined after 3 years. Like other plastic container systems, circling roots in the PiP system were still evident and could be anticipated to adversely impact plant health over a longer time period. Root structure and growth into the surrounding landscape soil was best for plants that were not restricted by plastic pots during production; e.g., field and BiP production systems.

\section{Literature Cited}

Adam, M.L., J.M. Kelly, W.R. Graves, and P.M. Dixon. 2003. Net nitrate uptake by red maple is a function of root-zone temperature. J. Plant Nutr. 26:203-222.

Adrian, J.L., C.C. Montgomery, B.K. Behe, P.A. Duffy, and K.M. Tilt. 1998. Cost comparisons for infield, above ground container and pot-inpot production systems. J. Environ. Hort. 16:65-68.

American Assoc. of Nurserymen. 1996. American standard for nursery stock. ANSI Z60.1-1996, Washington, DC.

Barr, W. and H. Pellet. 1972. Effect of soil temperature on growth and development of some woody plants. J. Amer. Soc. Hort. Sci. 97:632-635.

Gilman, E.F. 1988. Tree root spread in relation to branch dripline and harvestable rootball. HortScience 23:351-353.

Graves, W.R., M.N. Dana, and R.J. Joly. 1989. Root-zone temperature affects water status and growth of red maple. J. Amer. Soc. Hort. Sci. 114:406-410.

Hall, C., J. Haydu, and K. Tilt. 2002. The economics of producing nursery crops using the potin-pot production system: Two case studies. Southern Coop. Ser. Bul. 402:S-290 [Regional Project].

Havis, J.R. 1976. Root hardiness of woody ornamentals. HortScience 11:385-386.

Hodges, A.W., C.R. Hall, B.K. Behe, and J.H. Dennis. 2008. Regional analysis of production practices and technology use in the U.S. nursery industry. HortScience 43:18071812.

Ingram, D.L. and D.W. Buchanan. 1981. Measurement of direct heat injury of roots of three woody plants. HortScience 16:769771.

London, J., R.T. Fernandez, R.E. Young, and G.D. Christenbury. 1998. Comparing above-ground and in-ground pot-in-pot container systems. SNA Res. Conf. 43:71-75.

Lyr, H. and G. Hoffmann. 1967. Growth rates and growth periodicity of tree roots. Intl. Rev. of For. Res. 2:181-226.

Martin, C.A. and D.L. Ingram. 1993. Container dimension affects rooting medium temperature patterns. HortScience 28:18-19.

Miller, D.E. 1986. Root systems in relation to stress tolerance. HortScience 21:963-970.

Natl. Oceanic and Atmospheric Administration. 2001, 2002. Climatological data annual summary New England. Natl. Climatic Data Ctr., Asheville, NC. 22 June 2009. <http://www7. ncdc.noaa.gov/IPS/cd/cd.html>.

Neal, C. 2003. Crabapple growth and root-zone temperatures in field, container, and pot-in-pot production systems. HortScience 38:701 (Abstr.).

Newman, S.E. and F.T. Davies, Jr. 1988. High rootzone temperatures, mycorrhizal fungi, water relations, and root hydraulic conductivity of container-grown woody plants. J. Amer. Soc. Hort. Sci. 113:138-146.

Ruter, J.M. 1993. Growth and landscape performance of three landscape plants produced in conventional and pot-in-pot production systems. J. Environ. Hort. 11:124-127.

Ruter, J.M. 1997. The practicality of pot-in-pot. Amer. Nurse 8:32-37.

Ruter, J.M. 1998a. Fertilizer rate and pot-in-pot production increase growth of Heritage river birch. J. Environ. Hort. 16:135-138.

Ruter, J.M. 1998b. Pot in pot production and cyclic irrigation influence growth and irrigation efficiency of 'Okame' cherries. J. Environ. Hort. 16:159-162.

Studer, E.J., P.L. Steponkus, G.L. Good, and S.C. Wiest. 1978. Root hardiness of containergrown ornamentals. HortScience 13:172-174.

Watson, G.W. and E.B. Himelick. 1982. Root distribution of nursery trees and its relationship to transplanting success. J. Arboric. 8:225229.

Watson, G.W. and E.B. Himelick. 1997. Principles and practice of planting trees and shrubs. Intl. Soc. Arboric., Savoy, IL. 